\title{
Task-based Instruction and English Speaking Skill of Fluency in Jordanian Context
}

\author{
Sameer Mohammad Ali Al-Hirsh English Language Instructor \\ Department of Humanities, Al al-Bayt University, P.O. Box 130040 Mafraq 25113, Jordan
}

\begin{abstract}
This study investigates the effect of a Task-Based Instructional (TBI) program on Al al-Bayt University students' English speaking skill of fluency. A sample of 64 students was divided into three groups: a pilot study group, a control group and an experimental group. The experimental group was taught for eight weeks using a suggested TBI speaking program. The control group was taught for eight weeks using the teacher's book. To assess students' speaking skill of fluency, a speaking pre-post test was designed and a scoring scale was adapted. Students' responses were recorded on audio files. They were scored by two different raters and correlation coefficient was calculated. The findings of the study revealed that there were statistically significant differences at $(\alpha=0.05)$ in the mean scores of the fluency post test between the experimental group students and the control group students in favor of the experimental group students due to using the TBI program.
\end{abstract}

Key words: speaking fluency, English speaking skills, task-based instruction, instructional program

DOI: $10.7176 / \mathrm{JEP} / 12-9-08$

Publication date:March $31^{\text {st }} 2021$

\section{Introduction}

The main concern for teachers and learners of a second or a foreign language could be approximating native 'speakers' performance in that target language. Graham-Marr (2004) justified why teaching speaking skills is important. First, the fact that humans have been acquiring language through speaking and listening long before they began reading and writing. Second, our brains are well programmed to learn language through sound and speech. Fluency in teaching speaking implies that learners' speech does not look fragmentary, hesitant or even forced into silence leading to an impossible conversation. A successful speaking instructional program would make learners' speech effortless, less hesitant and somewhat similar to that of a native speaker.

Speaking is one key skill for most Teaching English as a Foreign Language (TEFL) instructional programs. It is argued that success in learning a language is measured in terms of the ability to carry out a conversation in the target language (Burkart and Sheppard, 2004; Nunan, 1999). Effective speaking instruction helps learners converse spontaneously and fluently with other speakers. Brown and Yule (1983) believed that speaking skills are the criteria for knowing a language. They concluded that learners assess their progress in terms of their accomplishments in spoken communication.

To Nunan (1989), speaking can be a dialogue or a monologue. A dialogue has to do with interacting with another speaker, which is a kind of interpersonal communication. However, a monologue has to do with giving an interrupted oral presentation, which is a kind of a presentational communication. In this regard, Brown and Yule (1983) pointed out that speaking can serve one of two functions: transactional functions to transfer of information (monologue) and interactional functions relevant to maintenance of social relationships (dialogue). Florez (1999) listed many speaking skills that need to be synthesized to achieve successful speaking tasks. A key speaking skill is paying attention to the success of the interaction and adjusting components of speech such as rate of speech to maximize listener's comprehension and involvement.

Teachers need to determine which speaking skills learners will focus on. They also need to identify which teaching strategy is suitable for each talk type. In the first type of talk as an interaction, teachers provide learners with examples in naturalistic dialogues such a opening and closing conversations, making small talks, and talking about personal past experience. In the second type of talk as transaction, communicative teaching materials could be the source for group activities, information-gap activities, and role plays. Here, talk is for sharing and obtaining information. Group discussions may be to let learners list some controversial statements. This talk type also involves using different communicative oral tasks. In the third type of talk as performance, teachers bring models of speeches, oral presentations and stories conveyed orally. This could be done by using video or even audio recordings.

Task Based-Instruction (TBI) approach does not predetermine what speaking skills are to be covered by teachers. The completion of a certain communicative task is an important aspect. What happens in the classroom guides speaking activities in the light of the planned goals. The procedural plan is first followed step by step, then it becomes automatic and spontaneous for both teachers and learners. It follows the computational system of input, processes, and output ( Richards, 2008). The task is the key element; something happens before, during and after it. 


\subsection{Statement of the Problem}

Poor and less fluent speaking performance of $\mathrm{Al}$ al-Bayt students makes up the problem of this study. Some previous research results share this problem, (Murad, 2009; Al-Jamal and Al-Jamal, 2014; and Al-Hamlan and Baniabdelrahman , 2015). The current study attempts to improve EFL students speaking performance with reference to fluency. Here, TBI may help students overcome speaking fluency problems.

\subsection{Purpose of the Study}

This study is carried out to investigate the effect of a TBI program on whether improving Al al-Bayt University EFL students' speaking skill of fluency or not.

\subsection{The Question of the Study}

This study addresses the following question: Are there any statistically significant differences at $(\alpha=0.05)$ between the mean scores of $\mathrm{Al}$ al-Bayt University students on the suggested speaking post-test in the speaking skill of fluency due to the use of the TBI program vs. the teacher's book teaching method?

\subsection{Significance of the Study}

Up to the researcher's knowledge, this study is the first to utilize a public Jordanian university students to investigate a TBI program on improving the English speaking skill of fluency. The study may contribute to modifying some teaching methods relevant to speaking. This study could encourage teachers to use TBI in teaching the English speaking skill of fluency.

\subsection{Limitations of the Study}

As it is difficult for a an empirical study to cover a very large population, this study will be restricted to the students of the Language Centre at Al al-Bayt University, Marfaq, Jordan. The results and findings of this study may be limited only within this population of students. A limited duration for implementing the proposed program may be another restriction. The period of the study is limited to eight weeks in the first semester of the academic year $2018 / 2019$.

\section{Review of Related Literature}

Different EFL teachers use different methods while teaching speaking. Some of them depend on what professional development workshops recommend and suggest. Others use either theoretical views to help them teach speaking or empirical studies of the effect of $\mathrm{x}$ and $\mathrm{y}$ on improving speaking skills. Many more teachers innovate their own methods as they do not have the opportunity to attend a workshop or a training course. Unfortunately, they even do not have access to any theoretical or empirical studies. Speaking instruction's big challenge emerges from the issue of evaluation and measurement.

As cited in O'Brien (1996: 3), Nunan (1991) listed five characteristics of task-based approach to language teaching. These characteristics emphasize on learning to communicate in the target language, on introducing authentic teaching materials into the learning process, and on enhancing the learner's personal experiences in the classroom learning environment. The tasks involved in this approach are mainly communicative in the sense that they focus on meaning rather than linguistic structures. The components of such tasks may include comprehending a message, manipulating learners' self-capabilities, and producing a meaning-focused message.

Nunan (2004) defined task-based language teaching and clarified the concept of a task. Focus was on experiential learning and the role of the learner. In the second chapter, a framework for task-based instruction was proposed. Seven principles for task-based language teaching were suggested. In the third chapter, tasks components and types were presented. In the fourth chapter, an empirical evidence was drawn in favor of taskbased language teaching. In the fifth chapter, focused and unfocused tasks were discussed. The importance of conscious-raising tasks was highlighted. In the last three chapters, grading, sequencing and integrating tasks were explained. Teachers' roles and the criteria for assessing task-based language teaching and self-assessment were all theoretically discussed.

Sanchez, A. (2004) attempted to describe (TBA) Task-Based Approach critically. Positive aspects of this approach were presented along with the inadequacy of some of its assumptions. It was argued that tasks could help in motivating students and in focusing the attention of teachers and learners on meaning and communicative language use. However; the debate on TBA reached the conclusion that it shouldn't be considered the method language teachers and learners had been waiting for.

While talking about important tasks of English education in Asia, Nunan (2005:6) suggested the following six attractive features of TBI:

1- TBI is a replacement to or a supportive infusion of more student centered learning.

2- TBI utilizes more authentic experience and materials as well as principles of constructivism compared to top down teaching 
3- TBI creates more of a sense of personal and active accomplishment including developing a greater sense of language ownership.

4- TBI increased students participations when task based teaching is well planned and implemented to be sensitive to learners' learning styles.

5- TBI makes specific lesson goals more evident through movement towards success of task completion.

6- TBI is an important, ongoing assessment and "wash-back" to both teacher and learner.

Shantha and Mekala (2017) conducted an experimental study on how to improve the English spoken proficiency of Indian engineering students using task-based approach. The study explored the pedagogical role that enables learners to improve their speaking skill. The participants were first year civil engineering students. They were 38 students in a control group and 38 students in an experimental group. The researchers used oral communicative tasks to think and generate sentences on their own orally. The results of the study revealed that there was a significant level of improvement in the oral proficiency of the experimental group.

Farabi, Hassanvand and Gorjian (2017) resorted to guided oral presentation in teaching English speaking skills. The researchers employed both guided and free oral presentations. The purpose of the study was to investigate whether guided or free oral presentation can develop Iranian EFL learners' speaking skills. The participants of the study were 60 homogenous female students from Andisheh English Language Institute. The results showed that the guided oral group outperformed the free oral group on the post-test. The researchers recommended that guided oral presentation could be useful in developing the speaking skills of pre-intermediate learners.

AlSaleem (2018) investigated the effect of Face-book activities on enhancing oral communication skills for EFL learners in the English Department at Yarmouk University, Jordan. The participants of the study were first year English Language B.A. students. The researcher hypothesized that practicing Face-book activities may improve learners' oral communication skills. The results of the study revealed that the suggested Face-book activities were effective on improving participants' oral communication skills. The study recommended that Facebook activities may even improved other skills of listening and pronunciation.

Torky (2006) aimed at identifying the speaking skills necessary for first year secondary school students, designing a task-based program in the light of the cognitive approach, constructing a proposed program to develop first year secondary school students' speaking skills, and measuring the effectiveness of the proposed program. The sample of the study consisted of 76 girl students ( 38 students as a control group and 38 students as an experimental group) from a Cairo governmental school. The findings of the study showed that the proposed taskbased program had the proof to be effective in developing first year secondary students' overall speaking performance.

Murad (2009) investigated the effect of a task-based language teaching program on developing the speaking skills of Palestinian secondary students and their attitudes towards English. The participants were 91 eleventh grade students ( 37 boys and 54 girls) from Bueina-Nujidat and Tamra High Schools. The findings of the study showed that the task-based language teaching program enhanced significantly the speaking skill of the experimental group students positively.

Mohammadipour and Rashid (2015) used a cognitive approach to investigate the impact of task-based instructional program on fostering learners' speaking ability. The study aimed at determining the effectiveness of a proposed task-based instructional program within a cognitive approach in fostering overall speaking proficiency of undergraduate students. 72 students from public universities participated in the study. The findings of the study showed a significant improvement in the overall speaking proficiency of the students who were exposed to the propose program.

Chen and Zhang (2015) employed task-based interaction pedagogy in English speaking instruction. the study investigated the effect of this teaching. The researchers adopted a quasi-experimental design. The sample of the study consisted of 70 Chemistry majors (42 males and 28 males) who had to take the college English speaking course. The findings of the study showed that the task-based interaction pedagogy was more effective in improving students' English speaking ability. Most of the students' English speaking abilities in the experimental group met the basic requirements of College English Curriculum Requirements, whereas many students in the control group did not.

Both theoretical and empirical studies encouraged and recommended using TBI to improve speaking skills. Several theoretical studies defined TBI and tasks explaining tasks components and presenting purposes, principles and characteristics of TBI. They also clarified roles of teachers and learners, O'brien (1996); Eliss (2000); Calvache (2003); Nunan (2004); Sanchez (2004) and Dickinson (2010). An increasing number of empirical studies investigated the effects of TBI programs on improving learners' oral performance in different EFL contexts, Torky (2006); Murad (2009); Aliakbari and Jamalvandi (2010); Ghodrati, Ashraf and Motallebzadeh (2014); and Alsagheer (2014) . Though TBI has lots of positive effects on improving speaking skills, it should not be taken as a one-size-fits-all, Bao and Du (2015). 


\section{Method}

\subsection{Participants of the Study}

The participants of the study were 64 volunteer students in three classes that were randomly selected from four English 101 course classes of the researcher's teaching schedule at the Language Centre of Al al-Bayt University, Marfaq, Jordan. That was in the first semester of the academic year 2018/2019. The 64-student sample was taken from three intact classes of the researcher's four classes which consisted of about 200 students. The participants were informed about an optional participation in this study by the researcher. They were motivated to participate as the study includes a teaching speaking program for free. Those who agreed to participate signed a consent form for that purpose (see Appendix A). They were given the chance to withdraw from the participation upon their free request at any time during the whole study period. About 12 students quitted the program for different individual reasons. To assure privacy and anonymity of the participants, they were given numbers as IDs. The sample was equally and randomly assigned and divided into a pilot study group of 24 students, a control group of 20 students and an experimental group of other 20 students. These participants were convenient for the researcher on that semester. Table (1) shows the distribution of the sample of the study according to the two independent groups: the control group and the experimental group.

Table 1 : Distribution of the participants of the study according to their groups

\begin{tabular}{|l|l|l|}
\hline Group & Students given IDs & Number \\
\hline Pilot Study & $1-24$ & 24 \\
\hline Experimental & $49-68$ & 20 \\
\hline Control & $25-44$ & 20 \\
\hline Total & 64 \\
\hline
\end{tabular}

\subsection{The TBI Program}

The researcher designed an instructional program based on TBI to achieve the purpose of the study. The instructional program followed specific instructional strategies, starting with brainstorming, questioning, clarifying and modeling. The roles of both the teacher and students were restricted within a pre-determined time framework. The researcher implemented each strategy by following specific steps in performing specific tasks to teach speaking skills with focus on fluency sub-skills of effortlessness of speech, in order to develop students' interaction and participation with the speaking audio materials

After the completion of this TBI program, students will be able to:

1 - interact and manage a conversation through encouraging the speaker to go on speaking, showing understanding, and turn-taking.

2- speak fluently at a reasonable rate of speech.

3- ask and answer questions sharing personal information.

4- accurately respond to an interviewer for a job.

5- correctly use directions like: go straight forward...go along these lanes...

6- describe a route using distances and timings like: The quickest way to reach...

7- talk and predict about the future

8- use phrases for giving advice and making suggestions

9- adequately describe people, pictures, and houses

10 - use polite requests and respond for someone' request positively

11 - ask for permission politely

\subsection{Instruments of the study}

\subsubsection{The Pre-Post Speaking Test}

The researcher designed a speaking pre-post test based on a review of the related previous literature. The pre-post test included both speaking activities and tasks. The speaking fluency skill components were measured using a well-structured open-ended questions developed by the researcher in accordance to the Teacher's Book of English 101 course. The learning and teaching objectives included in the teacher's book guided the development of the speaking test. The pre-test was intended to reflect the students' speaking performance levels on the individual and group levels before the administration of the TBI program to the experimental to verify if there is any effect of the program.

3.3.2 Students Oral Language Observation Matrix (SOLOM)

This instrument was originally developed by the San Jose Area Bilingual Consortium and had undergone revisions with leadership from the Bilingual Education Office of the California Department of Education. It is within the public domain and can be copied, modified, or adapted to meet local needs. As a rating instrument, this local SOLOM is adapted and modified to be restricted to only one component of fluency with five different levels: halting speech, hesitant speech, frequently disrupted speech, generally fluent speech with some lapses, fluent and effortless speech. 


\subsubsection{Validity and Reliability}

In order to validate the instructional program, the researcher presented it to a jury consisting of nine TEFL and linguistics university professors to look into its content and provide their feedback. Based on their suggestions, such as adding timing for each procedure in the lesson, unifying the format of the detailed lesson plans, omitting and modifying some tasks for time constraints, adding some more notes and instructions for both students' and teachers' evaluation at the end of each lesson. The researcher revised the instructional program and reproduced it in light of validating jury members' feedback. To judge the content validity of the test and linguistic suitability, the test was given to a jury consisting of nine TEFL and linguistics university professors, to look into its content and provide their feedback. The jury was asked to read the test and check the ambiguity, time and relevance of the test. Their comments and suggestions, such as deleting ambiguous questions, replacing them with clear questions, and checking all questions for clarity and simplicity, were taken into consideration in rewriting the questions of the test.

To establish the test reliability, the researcher carried out a pilot study with 24 students from the Language Centre at Al al-Bayt University, whom were excluded from the participants of the study. Inter rater reliability was established by asking two other teachers to score students' performance. For that purpose voice files were recorded for students performance on the pre-post tests. Pearson-correlation coefficients of the test-retest reliability were 0.885 for the first rater and 0.829 for the second rater (see table 2 ). The computed results of the reliability, which are appropriate values, indicate the reliability of the scale.

Table 2: Correlations of the participants of the pilot study scores of the test-retest for the first rater

\begin{tabular}{|l|ll|ll|}
\hline $\begin{array}{l}04-11-2018 \text { post } \\
\text { test }\end{array}$ & $\begin{array}{l}14-10-2018 \text { pre } \\
\text { test }\end{array}$ & & \\
\hline $.885(* *)$ & 1 & Pearson Correlation & $14-10-2018$ \\
.000 & & Sig. (2-tailed) & \\
24 & 24 & $\mathrm{~N}$ & $04-11-2018$ \\
1 & $.885(* *)$ & Pearson Correlation & \\
24 & .000 & Sig. (2-tailed) & \\
\hline
\end{tabular}

** Correlation is significant at the 0.05 level (2-tailed).

For the sake of reliability, the researcher and other two teachers will attend each student's test and fill in a separate rating sheet format of the adapted SOLOM. Tape-recording in the form of voice files for each student could help both raters put their rating after accurate and careful listening to each student's performance. Each rater may sit after the test finishes listening again and again to students' responses in order to give their ratings. An average of the two ratings will be calculated for each student out of fifteen points.

\section{Findings and Discussion}

Are there any statistically significant differences at $(\alpha=0.05)$ between the mean scores of the students on the suggested speaking post-test in the speaking sub-skill of fluency due to the use of the TBI program vs. teachers' book teaching method? In order to answer this question, means and standard deviations were calculated on the post-test. Table 3 presents the students' mean scores and standard deviations in the speaking skills of fluency in the pre-post test.

Table 3: The means and standard deviations of the students' mean scores in the speaking skill of fluency pre/post-test

\begin{tabular}{|l|l|l|l|l|l|}
\hline \multirow{2}{*}{ Group } & \multirow{2}{*}{$\mathbf{N}$} & \multicolumn{2}{|l|}{ Pre test } & \multicolumn{2}{l|}{ Post test } \\
\cline { 3 - 6 } & & Mean* & Std. Deviation & Mean* & Std. Deviation \\
\hline Experimental & 20 & 1.92 & .674 & 2.80 & 1.031 \\
\hline Control & 20 & 1.73 & .835 & 1.85 & .709 \\
\hline Total & 40 & 1.83 & .756 & 2.32 & .997 \\
\hline
\end{tabular}

*Means are out of 5

Table 3 shows that there are observed differences in the students' mean scores in the speaking skill of fluency post-test due to the use of the TBI program vs. the teacher's book teaching method. To check whether these differences were statistically significant at $(\alpha=0.05)$, ANCOVA test was applied. Table 4 presents the results. 
Table 4: ANCOVA results of the mean scores in the speaking skill of fluency post-test.

\begin{tabular}{|l|l|l|l|l|l|l|l|}
\hline Source & $\begin{array}{l}\text { Type III Sum of } \\
\text { Squares }\end{array}$ & $\begin{array}{l}\text { Mean } \\
\text { Df }\end{array}$ & Square & F & Sig. & $\begin{array}{l}\text { Partial } \\
\text { Squared }\end{array}$ \\
\hline $\begin{array}{l}\text { Fluency } \\
\text { (Covariance) }\end{array}$ & 3.028 & & 1 & 3.028 & 8.003 & $.008^{*}$ & .186 \\
\hline Group & 5.434 & 1 & 5.434 & 14.359 & $.001^{*}$ & .291 \\
\hline Error & 13.245 & 38 & .378 & & & \\
\hline Total & 38.775 & 39 & & & & \\
\hline
\end{tabular}

*Statistically significance at $(\alpha=0.05)$.

Table 4 shows that there are statistically significant differences in the mean scores of students' scores in the fluency speaking skill in the post-test due to the use of the TBI program vs. teacher's book teaching method. F value was 5.434 , which is statistically significant at $(\alpha=0.05)$. Therefore, there are statistically significant differences between the mean scores of the experimental group and the control group in the fluency speaking posttest due to the use of the TBI program vs. teacher's book teaching method. To find out which groups were more affected, the means and standard errors were measured. Table 5 presents these results.

Table 5: The adjusted mean scores and standard errors of students' scores of the fluency speaking skill in the post-test due to the use of the TBI program vs. the teacher's book teaching method

\begin{tabular}{|l|l|l|l|}
\hline test & Group & Mean & Std. Error \\
\hline \multirow{2}{*}{ Fluency } & Experimental & 2.727 & .144 \\
\cline { 2 - 4 } & Control & 1.923 & .144 \\
\hline
\end{tabular}

Table 5 shows that the adjusted mean scores of speaking skill of fluency for the experimental and control groups were 2.727 and 1.923 respectively and out of 5. In order to know the effect size, Eta square was measured in table 4 . It was 0.219 , which means that $21.9 \%$ of the variance in the total degree scores of the fluency speaking test was attributed to the teaching method using the suggested TBI program.

The results of the study showed that there were statistically significant differences at $(\alpha=0.05)$ between the mean scores of the experimental group and control group in the fluency speaking skills post-test in favor of the experimental group which was taught using the TBI program. It is indicated from the results that the students who were taught fluency speaking skills using the designed TBI program have improved their spoken production more smoothly. The researcher assumes that the nature of the designed program played a major role in improving students' speaking skills of fluency. The TBI program was designed carefully and was validated for implementation to achieve its purposes. The program depended on using some strategies of TBI: predicting, notetaking, role-playing, practicing, questioning and brain storming, summarizing, self-evaluating and reflecting to facilitate the interaction between the teacher and students and between students themselves. Moreover, the program included different tasks and different assessment tools to achieve its proper implementation.

One of the aims of the TBI program of this study was to improve students' fluency in speaking through considering individual differences among students. Therefore, the program was based on designing tasks suitable for group work and individual work to help students be more involved with the recordings they listen to, taking into consideration individual differences among students. The interactive nature of TBI let students become more engaged in the learning process rather than being passive recipients of information. It is worth mentioning that the main idea behind TBI is to encourage students to cooperate in understanding and analyzing the materials they are studying. The students in the experimental group became more fluent speakers and capable of self-evaluating their fluency sub-skill.

The researcher assumes that these differences are due to the nature of the TBI program, which focuses on improving the meta-cognitive skills in students. It is assumed that this could be achieved by using different TBI strategies. The levels of fluency speaking skill ranges from a halting and fragmentary speech that needs lots of building-confidence tasks to get rid of hesitance to everyday speech with occasional lapses moving to be fluent and effortless. However, what comes in between the levels of speaking fluency needs more effort from students and more patience from teachers. All levels of fluency require on-going evaluating processes with recurrent rehearsals. TBI strategies enable students from achieving this purpose more easily. The Practice stage of TBI, for example, helps students to produce and connect their speech with previous experiences to become more fluent giving them enough time to become more fluent. In addition, writing reports provided students with tools to reproduce speech in their own language to present their reports on the given tasks to their classmates and then to improve their interactional aspects.

With this TBI program, students were members of a social group or a community. They moved from dependence to autonomy as learning goes on. One of the concerns of the TBI program was fostering the process of participating well in conversations and getting students exposed to extended oral learning. Students used the target language more easily and effectively in many situations that start in the classroom and need to be completed outside the classroom. Students were given the chance to check their speed rate. Teachers repeated fluent reactions 
of students in front of their colleagues. All of these actions urged students to become more fluent speakers and moved them from being hesitant to confident and effortless speakers

The experimental group students were strongly influenced by the communicative nature of the tasks. As the tasks were real-life and approximating to what could students face in speaking with native speakers of English, students' rate of speed improved. The students felt that they need to speak and communicate, so they did their best to complete the unfinished tasks at home. They practiced and practiced oral language with more time outside the classroom. With such communicative tasks, the students lived the language, practiced it for longer time, and reflected on their experience. Students' speech turned to be more fluent and a little bit faster.

Before using the TBI program, the students' need-analysis presented in the speaking skill checklist showed that they pay a lot of effort with their speech flow. They also felt hesitant with lots of "um" and "ah". Although they speak loud enough, their rate of speed is very low, ranging from slow flow of speech to stopping. After using the TBI program, students feel that they became more fluent, clear and easy to follow, and less hesitant. The researcher believes that the statistically significant differences in the experimental group students' performance could be due to the positive interactivity of the tasks, and to bringing learning closer to real life. In the students' opinionnaire, students enjoyed TBI and believed that it improved their oral fluency a lot. They also feel that it became easier for them to become more fluent after using the TBI program.

The TBI program offered a set of chances to use pauses effectively in speaking. It also prepared students for less hesitant responses with less "um" and "ah". More focus on improving the rate of speed was shown. Some tasks train students to start a conversation, to introduce new ideas into a conversation, and to keep a conversation going on by asking questions. Focus on meaning was restricted to certain components of speaking functional language. These features of the TBI program could justify the improvement in the experimental group students' speaking fluency.

The TBI program provided students with the opportunity to learn from their classmates and share ideas and knowledge with them. The program also allowed students to become more fluent speakers in and out of the classroom, instead of being just listeners and receivers. The students became capable of exchanging information and opinions in a positive learning environment. These findings are in line with the findings of previous studies (e.g. Dincer, Yesilyurt, and Goksu, 2012; Wang, 2014; Seifoori, 2016; Albino, 2017; Thomson, 2017; Doe, 2017; Shahini and Shahamirian, 2017; Pishkar, Moinzadeh and Dabaghi, 2017). All these studies concluded with the importance of using TBI in improving students' fluency speaking skill.

\section{Conclusions}

Based on the findings of the study, the researcher concludes the following:

1- The Ministry of Higher Education and the administration of Al al-Bayt University in particular need to adopt the present instructional program in designing English language curriculum to include a variety of instructional strategies to teach speaking.

2- Conducting workshops and training sessions promote training teachers to use TBI in their classes to achieve more communicative learning outcomes.

3- EFL teachers would better use the present instructional program in teaching speaking skills of fluency in their classrooms to help students overcome speaking challenges.

4- Textbook authors, curriculum designers and EFL teachers are recommended to infuse TBI into their teaching materials and to focus on improving fluency in speaking skill sections.

\section{References}

Al-Hamlan, S. and Baniabdelrahman A. A. (2015). A needs analysis approach to EFL syllabus development for second grade students in secondary education in Saudi Arabia: A descriptive analytical approach to students' needs. American International Journal of Contemporary Research , 5 (1) , 118-145

Aliakbari, M. and Jamalvandi, B. (2010). The impact of 'role play' on fostering EFL learners' speaking ability: A task-based approach. Pan-Pacific Association of Applied Linguistics, 14 (1), 15-29

Al- Jamal, D. and Al-Jamal G. (2014). An investigation of the difficulties faced by EFL undergraduates in speaking skills. English Language Teaching, 7 (2), 19-27

Alsagheer, A. H. (2014). The effect of using task-based learning in teaching English on the oral performance of the secondary school students. International Interdisciplinary Journal of Education, 3 (2), 250-264

AlSaleem, B. (2018). The effect of Facebook activities on enhancing oral communication skills for EFL learners. International Education Studies, 11 (5), 144-153

Bao, R. and Du, X. (2015). Implementation of task-based language teaching in Chinese as a foreign language: Benefits and challenges. Language, Culture and Curriculum, 28 (3), 291-310

Brown, G. and Yule G. (1983). Teaching the spoken language: An approach based on the analysis of conversational English. Cambridge: Cambridge University Press

Burkart, G. and Sheppard K. (2004). Content ESL across the USA:A training packet. NY: Columbia University 
Calvache, E. (2003). Communicative approach, task-based approach and the development of competences in foreign languages. HOW Journal, 10 (1), 7-16

Chen, B. and Zhang, Y. (2015). An experimental study on task-based interaction in improving college students' English speaking ability. The $2^{\text {nd }}$ International Conference on Education Reform and Modern Management (ERMM), Atlantis Press

Dickinson, P. (2010). Implementing task-based language teaching in a Japanese EFL context : An assignment for an M.A. in applied linguistics, the University of Birmingham ,UK.

Ellis, R. (2000). Task-based research and language pedagogy. Language Teaching Research, 4 (3), 193-220

Farabi, M., Hassanvand, S. and Gorjian B. (2017). Using guided oral presentation teaching English language learners' speaking skills. Journal of Applied Linguistics and Language Learning, 3 (1), 17-24

Florez, M. A. (1999) . Improving adult English language learners' speaking skills. ERIC Digest, ERIC identifier: ED 435204

Gass, S. and Varionis E. (1994). Input, interaction and second language production. Studies in Second Language Acquisition, 16 (3), 283-302

Ghodrati, M., Ashraf, H. and Motallebzadeh, K. (2014). Improvement of Iranian EFL learners' autonomy through task-based speaking activities. International Journal of Multidisciplinary and Current Research, 2 (Sept/Oct.), 1002-1008

Graham-Marr, A. (2004). Teaching skills for listening and speaking. ELT (3), 23-31.

Hilferty, A. (2000). The relationship between reading and speaking skills: An interview. Focus on Basics, 4 (issue A)

Mohammadipour, M. and Rashid, S. (2015). The impact of task-based instruction program on fostering ESL learners' speaking ability: A cognitive approach. Advances in Language and Literary Studies (ALLS), 6 (2), 113-126

Murad, T. M. (2009). The effect of task-based language teaching on developing speaking skills among the Palestinian secondary EFL students in Israel and their attitudes towards English: A PhD dissertation, Yarmouk University, Jordan

Nunan, D. (1991). Communicative tasks and the language curriculum. TESOL Quarterly, 25 (2), 279-295

Nunan, D. (1999). Second language teaching and learning. Boston: Heinle \& Heinle Publishers

Nunan, D. (2004). Task-based language teaching. Cambridge: Cambridge University Press

Nunan, D. (2005). Important tasks of English education: Asia-wide and beyond. The Asian EFL Journal Quarterly, 7 (3), 5-8

O'Brein, M. (1996). Partners in learning: A task-based advanced speaking course. TESOL Convention, Chicago. ERIC Document, No. ED395472

Richards, J. C. (2008). Teaching listening and speaking from theory to practice. Cambridge: Cambridge University Press

Sanchez, A. (2004). The task-based approach in language teaching. International Journal of English Studies (IJES), 4 (1), 39-71

Severino, C. and Trachsel M. (2008). Theories of specialized discourses and writing fellows programs. Across the Disciplines : A Journal of Language, Learning and Academic Writing, retrieved from http://wac.colostate.edu/docs/atd/fellows/ severino.pdf

Shantha, S. and Mekala, S. (2017). The role of oral communicative tasks (OCT) in developing the spoken proficiency of engineering students. Advances in Language and Literary Studies (ALLS), 8 (2) 161-169

Torky, S. A. (2006). The effectiveness of a task-based instruction program in developing the English language speaking skills of secondary stage students: A Ph.D. thesis, Ain Shams University, Egypt

\footnotetext{
Appendix (A)

(A Consent Form for Participation in a Research Study Al al-Bayt University)

Title of Study

(Task-based Instruction and English Speaking Skill of Fluency in Jordanian Context )

Description of the research and your participation

You are invited to participate in a research study conducted by Sameer Mohammad Ali Al-Hirsh. The purpose of this research is investigating the effect of a TBI program on Al al-Bayt University students' speaking skill of fluency.

Your participation will involve:

1- Participating in a pre-post speaking test ; one time as a pilot study; another time before and after the TBI program

2- Tape-recording the tests each time.

3- Attending the whole sessions of the program which lasts for eight weeks.
} 


\section{Potential benefits}

It is expected that your English speaking performance may improve. This research may help us to understand whether the suggested TBI program is beneficial for students or not. If found beneficial, such program may be better included in the teaching material as a supplementary aid.

\section{Protection of confidentiality}

We will do everything we can to protect your privacy. Your identity will not be revealed in any publication resulting from this study.

\section{Voluntary participation}

Your participation in this research study is voluntary. You may choose not to participate and you may withdraw your consent to participate at any time. You will not be penalized in any way should you decide not to participate or to withdraw from this study.

\section{Consent}

I have read this consent form and have been given the opportunity to ask questions. I give my consent to participate in this study.

Participant's signature

Date: 